\title{
Lignin pyrolysis products: Their structures and their significance as biomarkers
}

\author{
C. Saiz-Jimenez*1 and J. W. DE LeeuW ${ }^{2}$ \\ 'Centro de Edafologia, C.S.I.C., Sevilla, Spain \\ ${ }^{2}$ Delft University of Technology, Department of Chemistry and Chemical Engineering. \\ Organic Geochemistry Unit, De Vries van Heystplantsoen 2, 2628 RZ Delft, \\ The Netherlands
}

(Received 17 September 1985; accepted 27 January 1986)

\begin{abstract}
Pyrolysis in combination with gas chromatography and mass spectormetry was used to characterize softwood, hardwood and grass lignins as well as the corresponding synthetic dehydropolymers. The method permitted differentiation of the three types of lignins. Softwood lignins yielded exclusively guaiacyl derivatives, coniferaldehyde and coniferyl alcohol being major compounds. Hardwood lignins gave rise to guaiacyl and syringyl derivatives, among which syringaldehyde, coniferyl alcohol and sinapyl alcohol were the most prominent. Grass lignins, represented by bamboo lignin, yielded $p$-vinylphenol as major compound. In addition, other guaiacyl and syringyl pyrolysis products were identified. The results indicate that guaiacyl and syringyl compounds are unique pyrolysis products of lignins and woods. Because of the relatively high resistance of lignins these pyrolysis products can be considered as characteristic biomarkers for terrestrial plant input.
\end{abstract}

Key words: milled wood lignins, dehydrogenative polymers, gymnosperm lignins, angiosperm lignins, grass lignins

\section{INTRODUCTION}

Lignins form an essential component of the woody stems of arborescent gymnosperms and angiosperms in which their amounts range from $15 \%$ to $36 \%$. Lignins are not, however, restricted to arborescent plants, but are found as integral cell wall constituents in all vascular plants including the herbaceous varieties.

Investigations on the chemistry of lignin have shown it to be a substance of great structural complexity. Its structure is based on molecular units of the phenylpropane type. The complexity of the lignin molecule arises in part from the manner in which the $\mathrm{C}_{6}-\mathrm{C}_{3}$ units are linked to each other (and in part from the fact that these units are not chemically identified).

Lignins are polymeric products arising from an enzyme-initiated dehydrogenative polymerization of three primary precursors: trans-coniferyl, trans sinapyl and trans-p-coumaryl alcohols.

The proportions of the three precursor alcohols differ between angiosperm and gymnosperm lignins. Gymnosperm lignin is made up by trans-coniferyl alcohol units, angiosperm lignin is constituted from trans-coniferyl and trans-sinapyl alcohol units and grass lignin contains all three alcohols as building blocks.

Living, dying and dead plants containing lignins are incorporated into soils and sediments, undergoing biochemical and chemical degradation reactions. Aerobic degradation of lignocellulose is slow since

*Address correspondence to: C. Saiz-Jimenez, Apartado $12.017,41080$ Sevilla, Spain. the presence of the lignin moiety severely decreases cellulose decomposition and because lignin is not the best microbial energy source. The absence of significant wood decomposition under anaerobic conditions is consequence of the requirement of oxygen for microbial degradation (Zeikus et al., 1982). Therefore, in soils lignins are slowly biodegraded by certain fungi and bacteria, and partly degraded lignins and lignin phenols may contribute to the formation of humus and are present in humic fractions (Saiz-Jimenez and de Leeuw, 1985), while in anaerobic wetlands and sediments of marine and freshwater environments, lignocellulosic materials are better preserved.

Lignin derivatives have been identified in soil organic matter fractions (Saiz-Jimenez and de Leeuw, 1984a, 1985), buried woods (Hedges et al., 1985), fossil woods (Sigleo, 1978; Hatcher et al., 1982) and kerogen (Habermehl and Hundrieser, 1983). Because lignin components are relatively stable upon diagenesis, they can be considered as specific biomarkers for terrestrial plant input.

In previous work, Saiz-Jimenez and de Leeuw (1984b) demonstrated that isolated, synthetic, biodegraded and kraft lignins can be analysed by flash pyrolysis. Further, pyrolysis-gas chromatographymass spectrometry (Py-GC-MS) data have shown a high correlation between pyrolysis products and the lignin units from which they arise (Martin et al., 1979; Obst, 1983). Therefore, it is possible to discriminate between gymnosperm and angiosperm lignins as original contributors to sediments and soils.

In this paper, Py-GC-MS of three types of isolated and synthetic lignins is reported. This study of soft- 
wood, hardwood and grass lignins and the characterization of their pyrolysis products will improve our present knowledge of the chemical structure of this biopolymer and will provide useful information when comparing sound, biodegraded, fossil or buried woods.

\section{EXPERIMENTAL}

\section{Samples}

Two spruce milled wood lignin samples (MWL) were provided by Dr T. Kent Kirk (MWL-1) and by Dr O. Faix (MWL-2). Beech, aspen and bamboo MWL samples were supplied by $\mathrm{Dr} O$. Faix. MWL samples were isolated according to Björkman (1956).

Dehydrogenation polymers (DHPs) were synthesized using trans-coniferyl, trans-sinapyl and trans-coumaryl alcohols in fixed proportions to reproduce the three types of lignins. They were kindly supplied by $\mathrm{Dr} O$. Faix. Further information on these samples is reported by Kirk and Chang (1984), Faix and Besold (1978), Martin et al. (1979) and Saiz-Jimenez and de Leeuw (1984b).

\section{Pyrolysis-GC and pyrolysis-GC-MS}

Details of the methods have been described in a previous paper (Saiz-Jimenez and de Leeuw, 1984b). Briefly, pyrolysis was performed with ferromagnetic wires having a Curie temperature of $510^{\circ} \mathrm{C}$ (pyrolysis time $10 \mathrm{sec}$ ) and pyrolysis products were separated on a capillary glass WCOT column $(28 \mathrm{~m} \times 0.5 \mathrm{~mm}$ i.d.) coated with $\mathrm{CP}$ sil $5(1.25 \mu \mathrm{m}$ film thickness) held at $50^{\circ} \mathrm{C}$ for $3 \mathrm{~min}$ and subsequently programmed to $250^{\circ} \mathrm{C}$ at a rate of $3^{\circ} \mathrm{C} \mathrm{min}-1$. He was used as a carrier gas.

\section{RESULTS}

Pyrograms of the MWL and DHP samples are shown in Figs 1-8. In this study we concentrated on

Table 1. Pyrolysis products from lignins

\begin{tabular}{|c|c|c|c|c|c|}
\hline Peak No. & $\mathbf{R}_{1}$ & $\mathbf{R}_{2}$ & $\mathbf{R}_{\mathbf{3}}$ & $\mathbf{R}_{4}$ & Remarks \\
\hline$i$ & $\overline{\mathrm{OH}}$ & & & & \\
\hline 2 & $\mathrm{OH}$ & $\mathrm{CH}_{3}$ & & & \\
\hline 3 & $\mathrm{OH}$ & & $\mathrm{CH}_{3}$ & & \\
\hline 4 & OH & $\mathrm{OCH}_{3}$ & & & \\
\hline $\begin{array}{l}5 \\
6\end{array}$ & OH & & $\mathrm{CH}_{2}-\mathrm{CH}_{3}$ & & Positional isomer of 7 \\
\hline 7 & $\mathrm{OH}$ & $\mathrm{OCH}_{3}$ & $\mathrm{CH}_{3}$ & & \\
\hline 8 & $\mathrm{OH}$ & & $\mathrm{CH}=\mathrm{CH}_{2}$ & & \\
\hline 9 & $\mathrm{OH}$ & & $\mathrm{CH}_{2}-\mathrm{CH}=\mathrm{CH}_{2}$ & & \\
\hline 10 & $\mathrm{OH}$ & $\mathrm{OCH}_{3}$ & $\mathrm{CH}_{2}-\mathrm{CH}_{3}$ & & \\
\hline $\begin{array}{l}11 \\
12\end{array}$ & $\begin{array}{l}\mathrm{OH} \\
\mathrm{OH}\end{array}$ & $\mathrm{OCH}_{3}$ & $\begin{array}{l}\mathrm{CH}=\mathrm{CH}-\mathrm{CH}_{3} \\
\mathrm{CH}=\mathrm{CH}_{2}\end{array}$ & & cis \\
\hline 13 & $\mathrm{OH}$ & $\mathrm{OCH}_{3}$ & & $\mathrm{OCH}_{3}$ & \\
\hline 14 & $\mathrm{OH}$ & $\mathrm{OCH}_{3}$ & $\mathrm{CH}_{2}-\mathrm{CH}=\mathrm{CH}_{2}$ & & \\
\hline 15 & $\mathrm{OH}$ & & CHO & & \\
\hline 16 & $\mathbf{O H}$ & $\mathrm{OCH}_{3}$ & $\mathrm{CH}_{2}-\mathrm{CH}_{2}-\mathrm{CH}_{3}$ & & \\
\hline 17 & OH & $\mathrm{OCH}_{3}$ & CHO & & \\
\hline 18 & $\mathrm{OH}$ & $\mathrm{OCH}_{3}$ & $\mathrm{CH}=\mathrm{CH}-\mathrm{CH}_{3}$ & & $c i s$ \\
\hline 19 & $\mathrm{OH}$ & $\mathrm{OCH}_{3}$ & $\mathrm{CH}_{3}$ & $\mathrm{OCH}_{3}$ & \\
\hline 20 & $\mathbf{O H}$ & $\mathrm{OCH}_{3}$ & $\mathrm{CH}_{2} \mathrm{CHO}$ & & \\
\hline 21 & $\mathrm{OH}$ & $\mathrm{OCH}_{3}$ & $\mathrm{CH}=\mathrm{CH}-\mathrm{CH}_{3}$ & & trans \\
\hline 22 & $\mathbf{O H}$ & $\mathrm{OCH}_{3}$ & $\mathrm{CO}-\mathrm{CH}_{3}$ & & \\
\hline 23 & $\mathrm{OH}$ & $\mathrm{OCH}_{3}$ & $\mathrm{COO}-\mathrm{CH}_{3}$ & & \\
\hline 24 & $\mathrm{OH}$ & $\mathrm{OCH}_{3}$ & $\mathrm{CH}_{2}-\mathrm{CH}_{3}$ & $\mathrm{OCH}_{3}$ & \\
\hline 25 & $\mathrm{OH}$ & $\mathrm{OCH}_{3}$ & $\mathrm{CH}_{2}-\mathrm{CO}-\mathrm{CH}_{3}$ & & \\
\hline 26 & $\mathrm{OH}$ & $\mathrm{OCH}_{3}$ & $\mathrm{CH}=\mathrm{CH}_{2}$ & $\mathrm{OCH}_{3}$ & \\
\hline 27 & $\mathrm{OH}$ & $\mathrm{OCH}_{3}$ & $\mathrm{CO}-\mathrm{CH}=\mathrm{CH}_{2}$ & & \\
\hline 28 & $\mathrm{OH}$ & $\mathrm{OCH}_{3}$ & $\mathrm{COOH}$ & & \\
\hline 29 & $\mathrm{OH}$ & $\mathrm{OCH}_{3}$ & $\mathrm{CO}-\mathrm{CH}_{2}-\mathrm{CH}_{3}$ & & \\
\hline 30 & $\mathrm{OH}$ & $\mathrm{OCH}_{3}$ & $\mathrm{CH}_{2}-\mathrm{COOH}$ & & \\
\hline 31 & $\mathrm{OH}$ & $\mathbf{O C H}_{3}$ & $\mathrm{CH}_{2}-\mathrm{CH}=\mathrm{CH}_{2}$ & $\mathrm{OCH}_{3}$ & \\
\hline 32 & $\mathrm{OH}$ & $\mathrm{OCH}_{3}$ & $\mathrm{CH}_{2}-\mathrm{CH}_{2}-\mathrm{CH}_{3}$ & $\mathrm{OCH}_{3}$ & \\
\hline 33 & $\mathrm{OH}$ & $\mathrm{OCH}_{3}$ & $\mathrm{CHO}$ & $\mathrm{OCH}_{3}$ & \\
\hline 34 & $\mathrm{OH}$ & $\mathrm{OCH}_{3}$ & $\mathrm{CH}=\mathrm{CH}-\mathrm{CH}_{3}$ & $\mathrm{OCH}_{3}$ & cis \\
\hline 35 & $\mathrm{OH}$ & $\mathrm{OCH}_{3}$ & $\mathrm{CH}=\mathrm{CH}-\mathrm{CH}_{2} \mathrm{OH}$ & & cis \\
\hline 36 & $\mathrm{OH}$ & $\mathrm{OCH}_{3}$ & $\mathrm{CH}_{2}-\mathrm{CHO}$ & $\mathrm{OCH}_{3}$ & \\
\hline 37 & $\mathrm{OH}$ & $\mathrm{OCH}_{3}$ & $\mathrm{CH}=\mathrm{CH}-\mathrm{CH}_{3}$ & $\mathrm{OCH}_{3}$ & Irans \\
\hline 38 & $\mathrm{OH}$ & $\mathrm{OCH}$, & $\mathrm{CO}-\mathrm{CH}_{3}$ & $\mathrm{OCH}_{3}$ & \\
\hline 39 & $\mathrm{OH}$ & $\mathrm{OCH}_{3}$ & $\mathrm{CH}=\mathrm{CH}-\mathrm{CHO}$ & & \\
\hline 40 & $\mathrm{OH}$ & $\mathrm{OCH}_{3}$ & $\mathrm{CH}=\mathrm{CH}-\mathrm{CH}_{2} \mathrm{OH}$ & & Irans \\
\hline 41 & $\mathrm{OH}$ & $\mathrm{OCH}_{3}$ & $\mathrm{CH}_{2}-\mathrm{CO}-\mathrm{CH}_{3}$ & & \\
\hline 42 & $\mathrm{OH}$ & $\mathrm{OCH}_{3}$ & $\mathrm{COO}-\mathrm{CH}_{3}$ & $\mathrm{OCH}_{3}$ & \\
\hline 43 & $\mathrm{OH}$ & $\mathrm{OCH}_{3}$ & $\mathrm{CO}-\mathrm{CH}=\mathrm{CH}_{2}$ & $\mathrm{OCH}_{3}$ & \\
\hline 44 & $\mathrm{OH}$ & $\mathrm{OCH}_{3}^{3}$ & $\mathrm{CO}-\mathrm{CO}-\mathrm{CH}_{3}$ & $\mathrm{OCH}_{3}$ & \\
\hline 45 & $\mathrm{OH}$ & $\mathrm{OCH}_{3}$ & $\mathrm{CH}_{2}-\mathrm{CH}_{2}-\mathrm{CH}_{2} \mathrm{OH}$ & $\mathrm{OCH}_{3}$ & \\
\hline 46 & $\mathrm{OH}$ & $\mathrm{OCH}_{3}$ & $\mathrm{CH}=\mathrm{CH}-\mathrm{CHO}$ & $\mathrm{OCH}_{3}$ & \\
\hline 47 & $\mathrm{OH}$ & $\mathrm{OCH}_{3}$ & $\mathrm{CH}=\mathrm{CH}-\mathrm{CH}_{2} \mathrm{OH}$ & $\mathrm{OCH}_{3}$ & trans \\
\hline
\end{tabular}

Note that the numbering of the ring atoms is different from the numbering used in Fig. 9. 


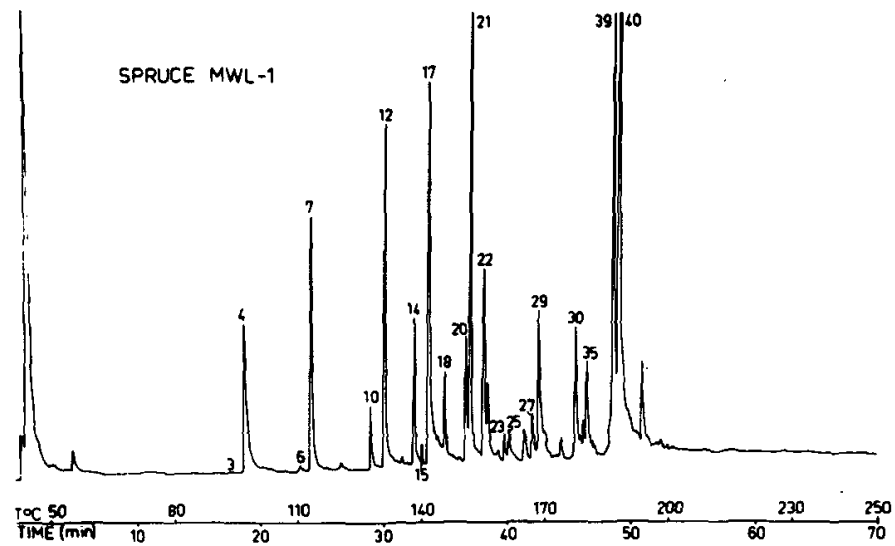

Fig. 1. Pyrogram of a Picea engelmanii milled wood lignin.

the phenolic pyrolysis products because they are highly representative of each lignin sample. Other products, like furan derivatives, which sometimes are present in the samples, and low molecular weight aromatic hydrocarbons such as benzene, toluene, styrene, alkylbenzenes, etc., are not discussed since they are minor pyrolysis products.

The structural elucidation of the pyrolysis products (Table 1) is based on comparison of both retention time and mass spectral data with those of standards and with literature data.

\section{Milled wood lignins}

Figure 1 shows the pyrogram of a spruce lignin (MWL-1). Major peaks are identified as 4-methylguaiacol (7), 4-vinylguaiacol (12), vanillin (17), transisoeugenol (21), coniferaldehyde (39) and transconiferyl alcohol (40). Other prominent pyrolysis products enountered are guaiacol (4), eugenol (14), homovanillin (20), acetoguaiacone (22), propioguaiacone (29) and homovanillic acid (30).

The other spruce lignin (MWL-2) analysed (Fig. 2) shows a high similarity with the MWL-I sample. The presence of a few additional furan derivatives and the decrease of the peaks corresponding to coniferaldehyde (39) and trans-coniferyl alcohol (40) are noted. Moreover, vanillic acid (28) is only present in this sample.

Differences between the two spruce samples analysed are expected to some extent because interspecies variation and variations within a single plant (e.g. normal and compression wood) lignins have been reported (Sarkanen and Hergert, 1971). Further, differences may also be ascribed to slight modifications in the analytical isolation procedures, although basically the same procedure was used in both laboratories.

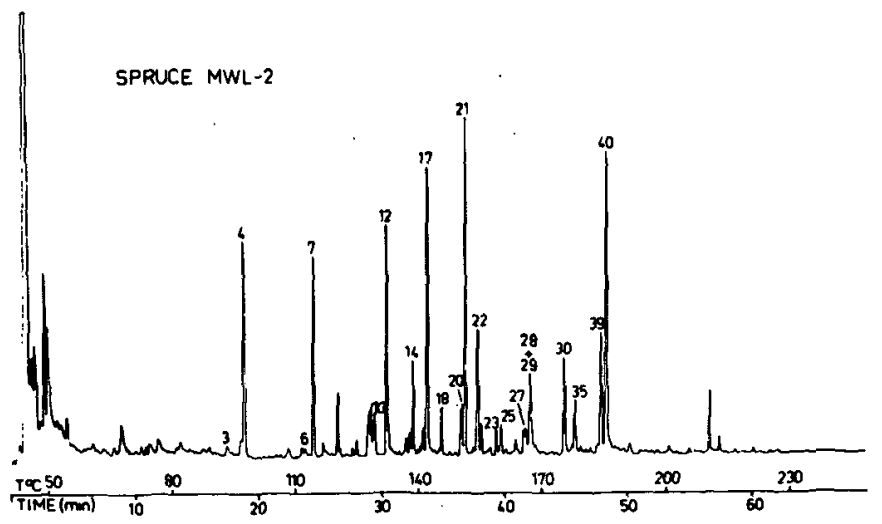

Fig. 2. Pyrograms of a Picea abies milled wood lignin. 


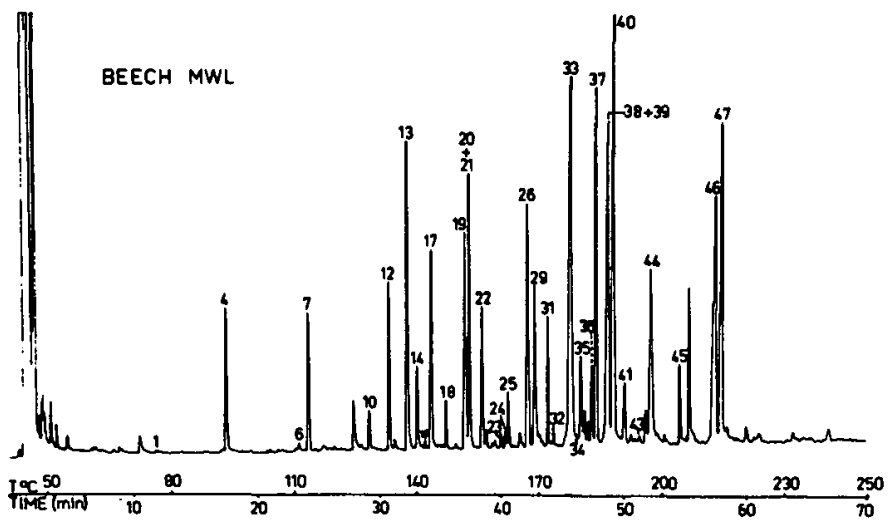

Fig. 3. Pyrogram of Fagus silvatica milled wood lignin. Contribution of acetoguaiacone (20) and acetosyringone (38) to the peaks are lesser than their corresponding coeluted compounds. A minor amount of dialkyl phthalate contributes to peak 46 . The contribution of the identified compound to peak 44 is minor as compared with a syringyl derivative of $\mathrm{MW} 210$ and unknown structure.

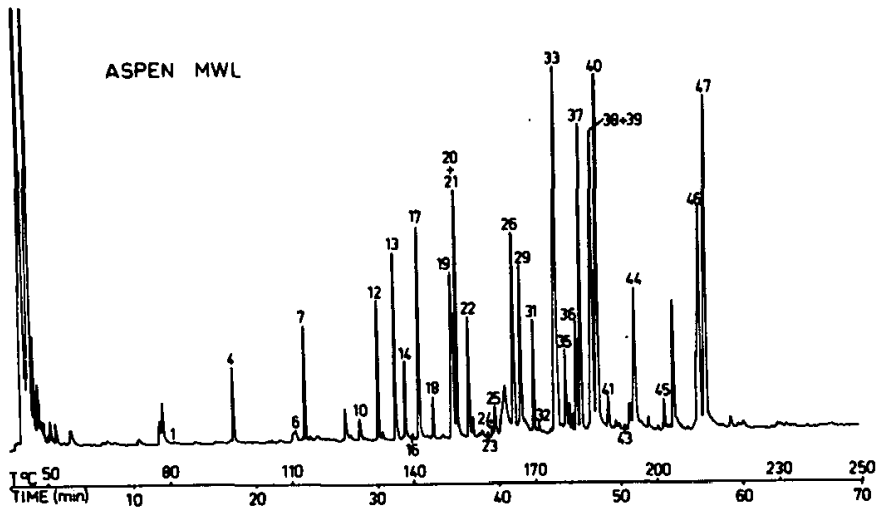

Fig. 4. Pyrogram of a Populus sp. milled wood lignin. Captions as in Fig. 3.

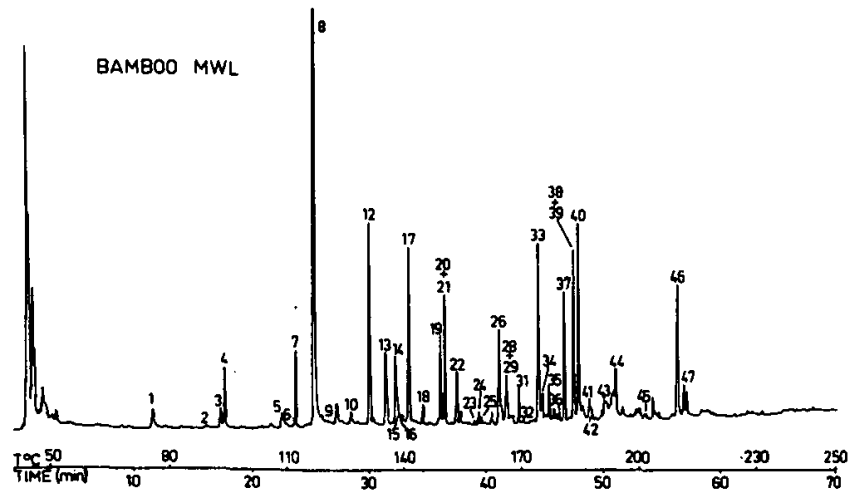

Fig. 5. Pyrogram of a Bambusa sp. milled wood lignin. Captions as in Fig. 3. 


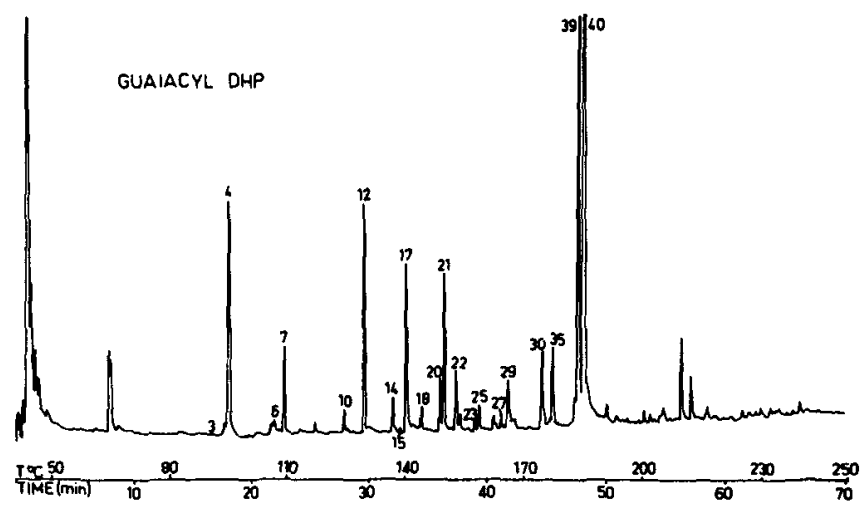

Fig. 6. Pyrogram of a guaiacyl dehydropolymer.

The pyrogram of beech MWL (Fig. 3) shows major peaks for 2,6-dimethoxyphenol (13), trants-isoeugenol (21), 4-vinyl-2,6-dimethoxyphenol (26), syringaldehyde (33), trans-4-propenyl-2,6-dimethoxyphenol (37), coniferaldehyde (39), trans-coniferyl alcohol (40), sinapaldehyde (46) and sinapyl alcohol (47). Prominent pyrolysis products are also guaiacol (4), 4-methylguaiacol (7), 4-vinylguaiacol (12), vanillin (17), 4-methyl-2,6-dimethoxyphenol (19), acetoguaiacone (22), propioguaiacone (29) and 4-allyl-2,6dimethoxyphenol (31).

The pyrogram of an aspen MWL (Fig. 4) is quite similar to those of beech lignin and only a few differences are found in peak intensities.

The pyrogram of bamboo MWL is shown in Fig. 5. In addition to typical guaiacyl and syringyl pyrolysis products $p$-hydroxyphenyl compounds, as known to occur in grass lignins, are observed. The major pyrolysis product identified is $p$-vinylphenol (8). Other important compounds are 4-vinylguaiacol (12), vanillin (17), trans-isoeugenol (21), syringalde- hyde (33), trans-4-propenyl-2,6-dimethoxyphenol (37), coniferaldehyde (39), trans-coniferyl alcohol (40) and sinapaldehyde (46).

\section{Dehydrogention polymers}

Guaiacyl DHP (Fig. 6) is similar to spruce MWLs in that both have the same type of pyrolysis products. However, the ratios of these products are different because compared to natural lignins the relative amounts of guaiacol (4), coniferaldehyde (39) and trans-coniferyl alcohol (40) are increased. This indicates differences between the natural and synthetic lignins probably in the proportion of linkages.

The pyrogram of the guaiacyl-syringyl DHP is displayed in Fig. 7. Major compounds are identified as 2,6-dimethoxyphenol (13), syringaldehyde (33), coniferaldehyde (39), trans-coniferyl alcohol (40), sinapaldehyde (46) and sinapyl alcohol (47). Other important compounds are 4-vinylguaiacol (12), vanillin (17) 4-methyl-2,6-dimethoxyphenol (19) transisoeugenol (21), 4-vinyl-2,6-dimethoxyphenol (26),

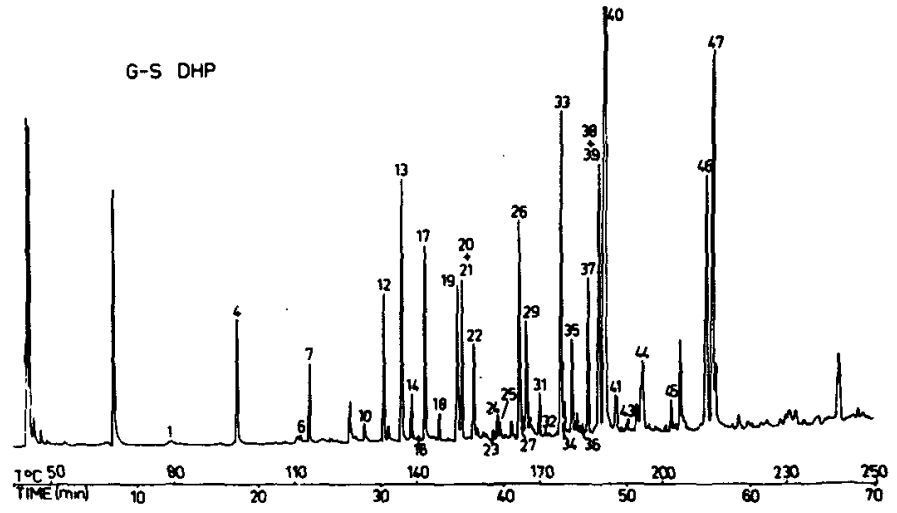

Fig. 7. Pyrogram of a guaiacyl-syringyl dehydropolymer. Captions as in Fig. 3. 


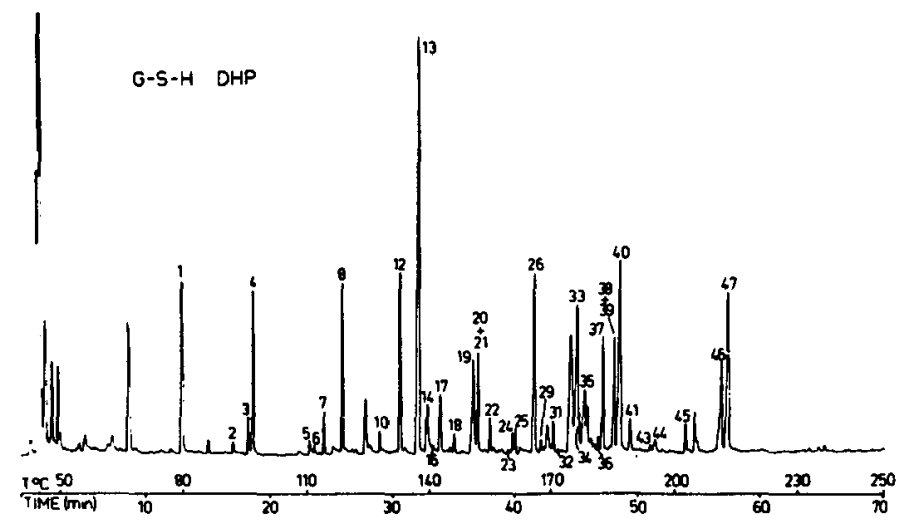

Fig. 8. Pyrogram of a guaiacyl-syringyl-p-hydroxyphenyl dehydropolymer. Captions as in Fig. 3.

and trans-4-propenyl-2,6-dimethoxyphenol (37). As for the guaiacyl DHP, the guaiacyl-syringyl DHP contains the same pyrolysis products as the natural lignin, but peak intensities are different, especially for trans-coniferyl alcohol.

The guaiacyl-syringyl-p-hydroxyphenyl DHP pyrogram (Fig. 8) shows a very different pattern with regard to bamboo MWL. The major phenolic compound identified is 2,6-dimethoxyphenol (13). Other prominent compounds are phenol (1), guaiacol' (4), p-vinylphenol (8), 4-vinylguaiacol (12), 4-vinyl-2,6dimethoxyphenol (26), syringaldehyde (33), trans coniferyl alcohol (40) and syringyl alcohol (47). In this case the synthetic lignin does not reproduce well the main linkages present in the bamboo MWL, as indicated by the very different relative amounts of pyrolysis products.

To further substantiate the possible pyrolysis mechanisms of p-coumaril alcohol precursors, a $p$-hydroxyphenyl DHP was also studied. Among the phenolic compounds $p$-cresol and trans-p-propenylphenol are abundant pyrolysis products. Other important compounds are phenol, $p$-ethylphenol, $p$ vinylphenol, $p$-propylphenol, cis-p-propenylphenol and $p$-coumarylalcohol. Most of them are also encountered in guaiacyl-syringyl-p-hydroxyphenyl DHP. The $p$-coumaryl alcohol peak is lower than any of the identified compounds in the pyrolysate of p-hydroxyphenyl DHP, which might explain the difficulty of identifying this compound in bamboo MWL and its synthetic counterpart.

\section{DISCUSSION}

\section{Pyrolysis products vs lignin units}

Lignins are thought to be composites of two relatively well defined structural moieties: the so-called "bulk-polymer" characterized by a large number of free $\mathrm{C}_{3}$-side chains and the "end-wise polymer", in which the $\beta-0-4$ linkage is dominant (Sarkanen,
1971). The identification of coniferaldehyde and coniferyl alcohol as major pyrolysis products in soft and hardwood lignins and their synthetic counterparts indicate that their presence is related with definite and relatively abundant structures. From all possible lignin substructures, two types, those with free end groups and those with arylglycerol- $\beta$-ether linkages appear to be the most likely candidates to explain the origin of these products. In fact, from units with free end groups the coniferyl derivatives will originate through cleavage of a $\mathrm{C}-\mathrm{O}$ bond. Most probably they are released from their association with the lignin molecule through the cleavage of a $\beta-0-4$ linkage (Fig. 9). In the case of ether structures, the cleavage of two or more $\mathrm{C}-\mathrm{O}$ bonds is involved. $\mathrm{C}-\mathrm{O}$ bonds are the relatively weakest linkages present among the structural units of lignins, which could explain the abundance of the encountered major coniferyl derivatives. Both types of the substructures mentioned might account for about $50 \%$ of the natural lignins and perhaps more in the synthetic ones.

$$
\beta-0-4 \text { CLEAVAGE }
$$

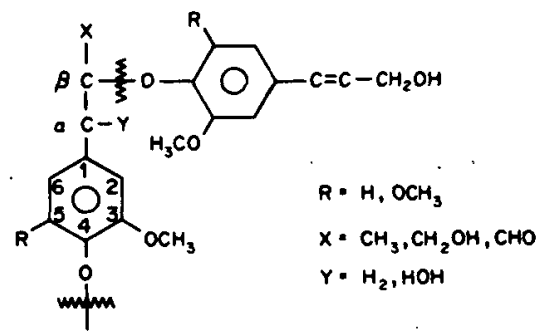

Fig. 9. Possible major types of lignin substructures thought to release coniferaldehyde/sinapaldehyde and coniferyl alcohol/sinapyl alcohol upon pyrolysis. Note that the numbering of the ring atoms in this figure is different from the numbering used throughout the text and in Table 1. 
The occurrence of sinapaldehyde and sinapyl alcohol also points to the presence of free end groups in syringyl substructures. In this case $\beta-0-4$ bonds are not so abundant because the dual $O$-substitution at positions 3 and 5 (Fig. 9) forms a barrier against $\beta-O$ couplings. Therefore, the $\beta-\beta$ coupling might be more important among syringyl units (Sarkanen, 1971).

The relatively lower intensities of sinapyl alcohol as compared to coniferyl alcohol in the aspen and beech MWL sample might be due to this more pronounced $\beta-\beta$ type of linkage, since these lignins are built up from almost equal amounts of coniferyl and sinapyl alcohols.

It is noteworthy that no hydroxyphenyl or syringyl compounds were encountered in the pyrolysates of softwood lignins, since Leopold and Malmström (1952) reported $p$-hydroxybenzaldehyde and syringaldehyde as minor components in the nitrobenzene oxidation of conifers.

Pyrolysis of bamboo MWL produces a rather unique suite of compounds (vinylphenol, propenylphenols, $p$-hydroxybenzaldehyde, etc.) that were not encountered in the softwood and hardwood lignins studied. Higuchi et al. (1967) reported that the larger proportion of $p$-hydroxybenzaldehyde produced in the alkaline nitrobenzene oxidation of grass lignins is formed from $p$-coumaric acid esterified with the lignin, and not from a $p$-hydroxyphenyl moiety in the lignin polymer itself. Further, these authors conclude that the main polymeric systems of the grass lignins are not very different from hardwood lignins. So, it is expected that the $p$-coumaric acid esterified with the lignin, upon pyrolysis, will yield the decarboxylated pyrolysis product $p$-vinylphenol.

\section{Milled wood lignins vs dehydrogenation polymers}

Milled wood lignins are considered to be, in many respects, almost identical with the original lignin, although they represent only $30-50 \%$ of the total lignin components, and generally contain small amounts of associated carbohydrates. The major differences between natural and synthetic lignins is the increase of coniferyl alcohol and aldehyde in the DHP samples, which indicates that an important moiety of the dehydropolymers is composed of the so-called "bulk polymer". In this connection, Haider et al. (1985) reported that ${ }^{13} \mathrm{C}$ labelling at the $\mathrm{C}-\gamma$ position of the side chain in the coniferyl alcohol precursor causes an enhancement of the signal corresponding to $\mathrm{C}-y$ of coniferyl alcohol units with a free chain, which was the most intense signal in the DHP spectrum. The same result was obtained with $C-\alpha$ and $C-\beta$ when labelled at the corresponding positions.

Spectroscopic and chemical studies point out that DHPs contain essentially the same structural units as MWLs (Kirk et al., 1975). Previous analytical pyrolysis (Saiz-Jimenez and de Leeuw, 1984b) demonstrated that spruce and synthetic lignins are similar in that both generate the same type of pyrolysis products. However, because the ratios of these products were different, it was concluded that MWL and DHP were not identical, but merely similar. Further, in this study it is shown that differences between hardwood lignins and their synthetic counterpart are also evident. However, the much larger differences observed between the bamboo MWL and the guaiacylsyringyl-p-hydroxyphenyl DHP indicate that the complexity of the natural lignin is not reflected in the synthetic one, probably due to the fact that the ester linkage is not present in the synthetic dehydropolymers.

\section{Present pyrolysis data vs literature data}

The results presented in this paper agree relatively well with those of Obst (1983) who studied loblolly pine and white oak MWL by Py-GC-MS. However, the different pyrolysis system (Pyroprobe) and temperature $\left(800^{\circ} \mathrm{C}\right)$ probably result in a higher fragmentation of subunits (e.g. demethylation, as indicated by the identification of catechols). Catechol was only found upon Curie-point pyrolysis in biodegraded and kraft lignins (Saiz-Jimenez and de Leeuw, 1984b), where the action of respectively fungi and chemicals cause a demethylation. In the investigation reported here no catechols were encountered.

Martin et al. (1979) studied the same MWLs as those reported here. Also, in this case the pyrolysis system (Pyroprobe) and temperature $\left(700^{\circ} \mathrm{C}\right)$ were different. The distribution patterns of pyrolysis products were somewhat different from those reported here. The largest difference concerned their identification of vinylphenols in the spruce $\mathrm{MWL}$ (equivalent to our MWL-2). A detailed study of the two spruce and the beech and aspen MWL samples failed to recognize vinylphenols among the pyrolysis products. Therefore, it is possible that the pyrolysis conditions used by the authors caused fragmentation of guaiacyl units to give rise to vinylphenols. However, Obst (1983) using an even higher temperature also did not report vinylphenols in pine and oak MWL.

From these data it must be concluded that comparison of results, even obtained for the same samples using different analytical systems and pyrolysis temperature is difficult.

Philp et al. (1982) studied lignins using Curie-point pyrolysis with an end temperature of $610^{\circ} \mathrm{C}$. In pine lignin, among other compounds, 1,4-dimethoxybenzene and 1,2,3-trimethoxybenzene were identified and in eucalyptus lignin the major compound was identified as 3,4-dimethoxyphenol. Neither of these compounds could be identified in softwood and hardwood lignins by Obst (1983) or in this study, as expected, because there are no parent structures present in lignins which can give rise to them upon pyrolysis. As suggested by Obst (1983) identifications might have been wrong owing to misinterpretation of library spectra. This could occur because many of the 
lignin pyrolysis products are not present in most library files and the best match does not always give the right structure. Reinterpretation of the data is necessary before a comparison can be made.

Sigleo (1978) reported that wood polymers survive 200 million years of silicification and diagenesis in the Petrified Forest National Park (Arizona) while Habermehl and Hundrieser (1983) found typical lignin oxidation products in Messel kerogen, 50 million years old. Because the guaiacyl and syringyl derivatives are unique to lignins and woods, and obviously can be preserved for millions of years, lignins can be considered as macromolecular biomarkers. Unequivocal evidence for the presence of lignin and/or wood in fossil materials can be obtained by studying the pyrolysis products. Moreover, Py-GC-MS analysis can clearly distinguish the three types of lignins.

The presence of $p$-vinylphenol as major compound in the pyrolysates of lignocellulosic materials, in addition to guaiacyl and syringyl derivatives, points to grass lignin. Guaiacyl and syringyl derivatives, in absence of $p$-hydroxyphenyl compounds, direct to hardwoods, while the presence of guaiacyl units alone indicate that the lignin was biosynthesized by conifers. To further prove these statements and to obtain more information about the fate of buried wood components such as carbohydrate and lignin structures, a study of spruce, alder and oak woods deposited in coastal sediments is in progress.

\section{Note added in proof}

Unidentified peak before 10 in Figs $3,4,5,7$ and 8 is methoxydihydroxybenzene. Also peak before 46 is as-sinapyl alcohol.

Acknowledgement - Part of this research was supported by CSIC, Spain, Grant 781.

\section{REFERENCES}

Björkman A. (1956) Studies on finely, divided wood. Part I. Extraction of lignin with neutral solvent. Svensk Papperstidn. 59, 477-485.

Faix O. and Besold G. (1978) Herstellung und Charakterisierung von Dehydrierungspolymerisaten von $p$-HydroxyZimtalkoholen (DHPs) unter besonderer Berücksichtigung von reinen 4-Hydroxy-Phenyl-(H-), Guajacyl-(G-) und syringyl-(S-)propan-Polymerisaten. Holzforschung 32, 1-7.

Habermehl G. and Hundrieser H.-J. (1983) 50 Millionen Jahre altes Coniferen-Lignin aus Messel. Naturwissenschafien 70, 249-250.

Haider K., Kern H. W. and Ernst L. (1985) Intermediate steps of microbial lignin degradation as elucidated by ${ }^{13} \mathrm{C}$ NMR spectroscopy of specially ${ }^{13} \mathrm{C}$-enriched DHP. lignins. Holzforschung 39, 23-32.
Hatcher P. G., Breger I. A., Szeverenyi N. M. and Maciel G. E. (1982) Nuclear magnetic resonance studies of ancient buried wood-II. Observations on the origin of coal to the brown coal stage. Org. Geochem. 4, 9-18.

Hedges J. I., Cowie G. L., Ertel J. R., Barbour R. J. and Hatcher P. G. (1985) Degradation of carbohydrates and lignins in buried woods. Geochim. Cosmochim. Acta 49, $701-711$.

Higuchi T., Ito Y. and Kawamura 1. (1967) p-Hydroxyphenylpropane component of grass lignin and role of tyrosine-ammonia lyase in its formation. Phytochem. 6 , 875-881.

Kirk T. K. and Chang H.-M. (1974) Decomposition of lignin by white-rot fungi. I. Isolation of heavily degraded lignins from decayed spruce. Holzforschung 28, 217-222.

Kirk T. K., Connors W. J., Bleam R. D., Hackett W. F. and Zeikus J. G. (1975) Preparation and microbial decomposition of synthetic ${ }^{14} \mathrm{C}$-lignins. Proc. Not. Acad. Sci. U.S.A. 72, 2515-2519.

Leopold B. and Malmström I.-L. (1952) Studies on lignin. IV. Investigation on the nitrobenzene oxidation products of lignin from different woods by paper partition chromatography. Acta Chem. Scand. 6, 49-54.

Martin F., Saiz-Jimenez C. and Gonzalez-Vila F. J. (1979) Pyrolysis-gas chromatography-mass spectrometry of lignins. Holzforschung 33, 210-212.

Obst J. R. (1983) Analytical pyrolysis of hardwood and softwood lignins and its use in lignin-type determination of hardwood vessel elements. $J$. Wood Chem. Technol. 3 , 377-397.

Philp R. P., Russel N. H., Gilber T. D. and Friedrich J. M. (1982) Characterization of Victorian soft brown coal wood by microscopic techniques and Curie-point pyrolysis combined with gas chromatography mass spectrometry. J. Anal. Appl. Pyrol. 4, 143-161.

Saiz-Jimenez C. and de Leeuw J. W. (1984a) Pyrolysis gas chromatography mass spectrometry of soil polysaccharides, soil fulvic acid and polymaleic acid. In Aduances in Organic Geochemistry 1983 (Edited by Schenck P. A. de Leeuw J. W. and Lijuibach G. W. M.) Org. Geochem. 6, 287-293. Pergamon Press, Oxford.

Saiz-Jimenez C. and de Leeuw J. W. (1984b) Pyrolysis-gas chromatography-mass spectrometry of isolated, synthetic and degraded lignins. In Advances in Organic Geochemistry 1983 (Edited by Schenck P. A., de Leeuw J. W and Lijuibach G. W. M.) Org. Geochem. 6, 417-422. Pergamon Press, Oxford.

Saiz-Jimenez C. and de Leeuw J. W. (1986) Chemical characterization of soil organic matter fractions by analytical pyrolysis-gas chromatography-mass spectrometry. J. Anal. Appl. Pyrol. 9, 99-119.

Sarkanen K. V. and Hergert H. L. (1971) Classification and distribution. In Lignins: Occurrence, Formation, Structure and Reactions (Edited by Sarkanen K. V. and Ludwig C. H.), pp. 43-94. Wiley-Interscience, New York.

Sarkanen K. V. (1971) Precursors and their polymerization. In Lignins: Occurrence, Formation, Structure and Reactions (Edited by Sarkanen K. V. and Ludwig C. H.), pp. 95-163. Wiley-Interscience, New York.

Sigleo A. C. (1978) Degraded lignin compounds identified in silicified wood 200 million years old. Science 200,1054 1056.

Zeikus J. G., Wellstein A. L. and Kirk T. K. (1982) Molecular basis for the biodegradative recalcitrance of lignin in anaerobiotic environments. FEMS Microbiol. Lett. 15, 193-197. 